\title{
GCU
}

Glasgow Caledonian

University

University for the Common Good

\section{On-line condition monitoring of power transformer health status enforced by temperature and electrical signatures}

Aburaghiega, Ehnaish; Farrag, Mohamed Emad; Gouda, Mohamed Mahmuod

Published in:

Proceedings of the 2019 21st International Middle East Power Systems Conference (MEPCON)

DOI:

10.1109/MEPCON47431.2019.9008023

Publication date:

2020

Document Version

Author accepted manuscript

Link to publication in ResearchOnline

Citation for published version (Harvard):

Aburaghiega, E, Farrag, ME \& Gouda, MM 2020, On-line condition monitoring of power transformer health status enforced by temperature and electrical signatures. in Proceedings of the 201921 st International Middle East Power Systems Conference (MEPCON)., 123, 2019 21st International Middle East Power Systems Conference, MEPCON 2019 - Proceedings, IEEE, pp. 521-526, 2019 21st International Middle East Power Systems Conference (MEPCON), Cairo, Egypt, 17/12/19. https://doi.org/10.1109/MEPCON47431.2019.9008023

\section{General rights}

Copyright and moral rights for the publications made accessible in the public portal are retained by the authors and/or other copyright owners and it is a condition of accessing publications that users recognise and abide by the legal requirements associated with these rights.

Take down policy

If you believe that this document breaches copyright please view our takedown policy at https://edshare.gcu.ac.uk/id/eprint/5179 for details of how to contact us. 


\section{On-line Condition Monitoring of Power Transformer Health Status Enforced by Temperature and Electrical Signatures}

\author{
Ehnaish Aburaghiega ${ }^{1}$ \\ ${ }^{1}$ School of Computing, Engineering and \\ Built Environment \\ Glasgow Caledonian University \\ Glasgow, UK \\ Ehnaish.Aburaghiega@gcu.ac.uk
}

\author{
Mohamed Emad Farrag ${ }^{1,2}$ \\ ${ }^{1}$ School of Computing, Engineering and Built \\ Environment \\ Glasgow Caledonian University \\ Glasgow, UK \\ ${ }^{2}$ Faculty of Industrial Education, Helwan \\ University, Egypt \\ Mohamed.Farrag@gcu.ac.uk
}

\author{
Mohamed Mahmuod Gouda ${ }^{2}$ \\ ${ }^{2}$ Faculty of Industrial Education, Helwan \\ University, Egypt \\ mohamedgouda@techedu.helwan.edu.eg
}

\begin{abstract}
Transformers play a vital role in the electrical power system network, loss of a power transformer has severe consequences on both the utility and customers depending on how long time it is out-of-service. Internal faults are said to be the most likely cause of disruption in transformer's performance and, consequently, interruption of power supplied. Developing an on-line method to monitor and investigate the health of a transformer will help asset managers to assess infrastructure while it is operational, leading to reduced running costs and increased component life. This research develops methods of on-line and on-going condition monitoring of power transformers based on monitoring the transformer signatures (voltage and current on both sides of the transformer), winding and core temperature. An experimental study has been conducted to investigate the behaviour of a transformer under healthy and unhealthy conditions. A transformer designed to provide access to sections/turns terminals was used to generate short circuit test in different locations during operational time, thermocouples are distributed across the transformer windings' discs in order to record their temperature during normal and abnormal operation. The results confirm the possibility of, in real time, detecting the presence of a short circuit fault, indicating its location and its severity. The correlation between the measured variables indicate the magnitude of the circulating current, thus the fault severity can be classified. The transformer temperature may also indicate the faulty windings and moreover which disc in each winding is short circuited.
\end{abstract}

Keywords-Transformer diagnostics, Continuous On-line monitoring, Temperature, Fault detection, fault location, Severity.

\section{INTRODUCTION}

A power transformer is a critical and vital part of the equipment in an electrical network. These devices transfer power between different levels of voltage and current, depending on the turns ratio, with constant frequency [1]. Analysis has shown that large numbers of transformers have been damaged or set on fire because of transformer ageing, bad manufacturing, voltage interruption, lightning bolt strike, etc. [2]. Sudden outage of a power transformer can cost millions of pounds, depending on the period of time the transformer was out of service and also due to replacement or repair cost. To avoid these problems, investigation of condition monitoring and evaluation techniques of power transformers has become a subject of interest for many researchers, to identify power transformer faults and leading to extending their life cycle [3]. On-line condition monitoring and evaluation techniques have been used in different studies, e.g. [4]. These researches have shown that on-line monitoring of power transformer can be successfully applied for fault diagnosis and maybe protection during its operation.

Assessing the transformer performance and its on-line behaviour under occurrence of short circuit is very important and continuously being a hot research topic for commercial electric companies [5]. This is due to the fast increase in concerns over the energy efficiency in the electricity network, this is definitely affected by the failure of the grid components, in particular power transformers. Authors in [6] have determined that advanced on-line diagnosis and fault detection should be adopted in the modern grids.

Nowadays, understanding the relationships between electrical signals that are related to transformer both electrical and mechanical conditions has become necessary, this can be achieved based on applying different techniques [7], e.g. Sweep Frequency Response Analysis (SFRA) [8], Short-Circuit Impedance (SCI) [9]. Winding Resistance [10] or Finite Element method [11]. In addition, poor mechanical strength of components and insulation may cause a collapse of windings and deformation or damage to clamping structures [12] as a result of magneto-motive forces under short-circuit conditions. Leakage Inductance Calculation [13] and short circuit test under Impulse Excitation [14] have been introduced in order to improve the accuracy of the information collected for inter-turn short circuit fault detection. Many of these methods require that the transformer is taken out of service for testing: this is a huge disadvantage of off-line methods as operators would prefer that a transformer was not disconnected from the power grid for testing.

Several techniques have been introduced in recent research studies, in order to determine the existence of interturn short circuit e.g. extraction of winding parameters of a single-phase transformer based on primary and secondary currents and voltages [15], a method based on the use of noload and light load current harmonic analysis [16], winding deformations based on the Lissajous graphical analysis of voltage and current [17], instantaneous voltage and current measurements [18] and a novel online technique to detect power transformer winding fault [19]. This research provides the opportunity to apply continuous on-line condition monitoring to a transformer and provides the ability to indicate fault location and severity. These advantages are not available in the methods mentioned earlier.

In [20], authors addressed the possibility of adopting online as a replacement of off-line condition monitoring of a power transformers based on the detection and monitoring of internal short circuit. 
In this work, an experimental study of the behaviour of a transformer under normal and abnormal conditions has been focused upon. Purposely manufactured with access to every turn transformer, $3 \mathrm{kVA}, 230 \mathrm{~V}, 50 / 60 \mathrm{~Hz}$, has been used to conduct the suggested experiments for imitating continuous online condition monitoring of a power transformer, this was conducted based on continuous monitoring of the transformer's voltage and current signatures and temperatures. Temperatures are recorded using thermocouples distributed inside the transformer housing. LabView software has been used to collect the transformer's signatures and temperature data. Healthy and faulty transformers will be tested in order to investigate the possibility of applying continuous on-line monitoring of the transformer based on a transformer's voltages, currents and temperature of the core and windings.

\section{Proposed ApProACH}

The indoor transformer described in [21] has been used for considering methods of continuous condition monitoring when supplying constant load loads. A schematic of the transformer was designed and manufactured to conduct this research is shown in Figure. 1, where P.D1 to PD4 represents Primary Disc 1 to Primary Disc 4 and, SD1 to SD4 represent Secondary Disc 1 to Secondary Disc 4, respectively.

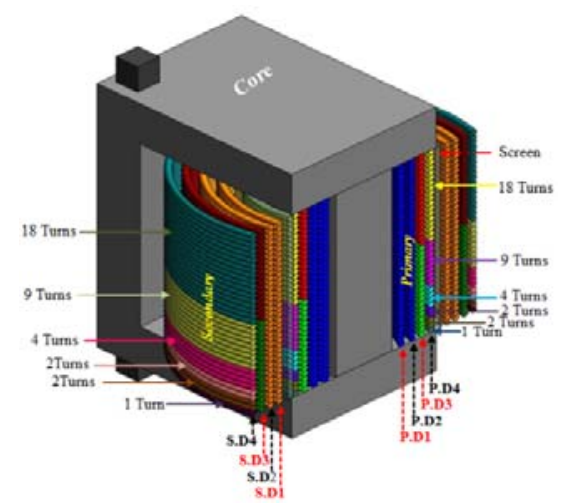

Figure 1: Winding construction, showing discs and number of turns

A programmable load is connected to the secondary side of the transformer and used to establish the transformer behaviour for different loads. A $(\mathrm{PM}+1000)$ power analyser is used to measure the voltage and current in the primary side of the transformer and the programmable load defines the applied load and measures the secondary voltage and current. $16 \mathrm{~K}$ type thermocouples are distributed across the transformer windings' discs in order to record their temperature during normal and abnormal operation. There are three additional thermocouples, two of them are located on the top and bottom of the core and the third is located outside the winding housing in order to measure the ambient temperature. The thermocouples are connected to a data logger that is recording directly the measured temperature using LabView software according to the standard stated in [22]. All temperatures, primary and secondary winding voltage and current data are recorded at the lowest possible sampling intervals for the used equipment of 30 seconds.

\section{Healthy TRANSFORMER}

The health of the transformer insulation has been tested before performing the experiment using appropriate instruments. The laboratory power supply can provide different levels of voltages 0 to $245 \mathrm{~V}$, voltages and currents are measured and recorded via NI hardware and LabView software. Figure 2 shows one to one turns ratio winding construction and thermocouples' distribution of the tested transformer as described in Figure 1.

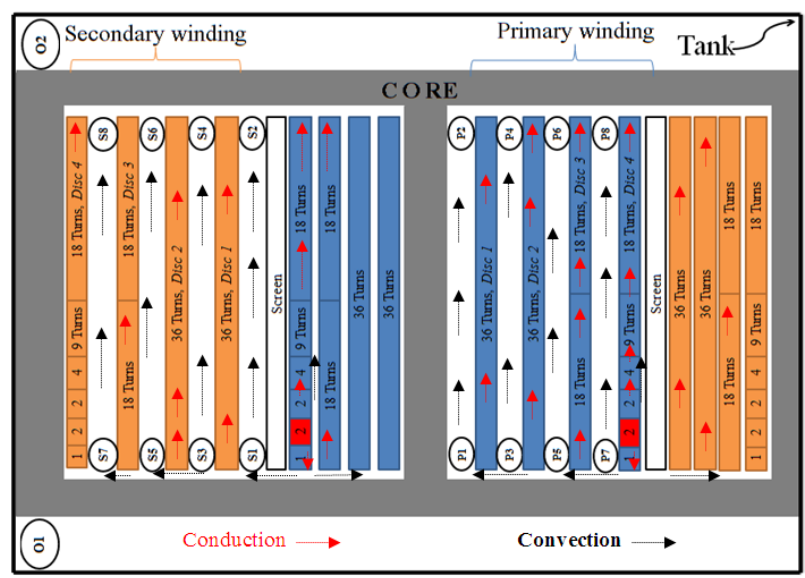

Figure 2: Schematic of transformer showing thermocouple positions

The thermocouples are connected to the LabView controlled data logger that has a range of $\pm 10 \mathrm{~V}$ and has a built-in sensor to measure the ambient temperature; the data logger is connected to a laptop to display and save the temperature records.

As illustrated in the figures above, windings are concentric, the secondary winding is outside the primary winding and isolated by a screen between the turns/discs. 8 thermocouples are distributed at the top and bottom of the primary winding, referenced as $\mathrm{P} 1$ to $\mathrm{P} 8$, another 8 thermocouples are sited at the top and bottom of the secondary winding discs, referenced as $\mathrm{S} 1$ to S8. The thermocouple (T-Top) (O2) is located at the top of the core and measures the temperature of the surface of the core, (T-Bottom) (O1) measures the temperature at the bottom of the transformer core and T-ambient is located in the laboratory to measure the room's ambient temperature. Figure 3 illustrates the experimental layout and connection of various components.

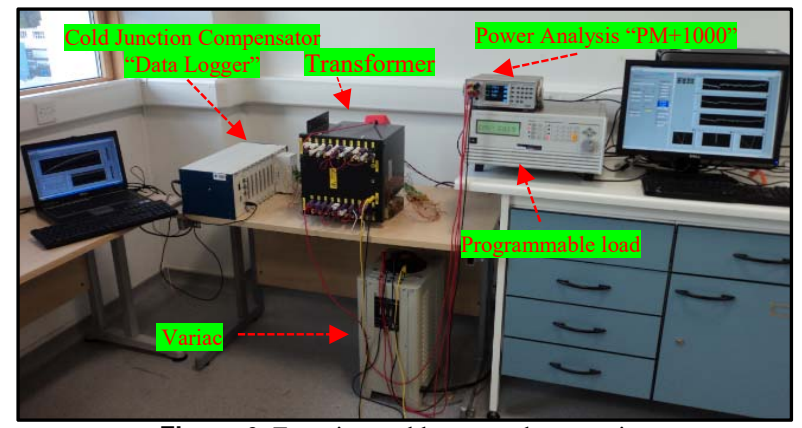

Figure 3: Experimental layout and connection

\section{A. Voltage and Current Signature for Heathy Trnsaformer}

For on-going condition monitoring the transformer rated power is $3 \mathrm{kVA}(50 \mathrm{~Hz})$, in this work, the programmable load provides different resistive loads of up to $1.8 \mathrm{~kW}$, which represents $60 \%$ of the transformer rated power. In this research, data of the $30 \%$ loading is presented, the transformer operated for 20 hours, and data were recorded to consider the steady state temperature, the voltage and current signatures in both sides of the transformer. Figure 4 
demonstrates the voltage variation in both sides of the transformer for the connected load; the secondary voltage is following the primary winding voltage's behaviour and the difference due to the winding losses remains constant. All measurements are sampled every 30s. The primary and secondary current over the same period are shown in Figure 5 , the supply voltage variation also affects the current behaviour leading to similar profiles.

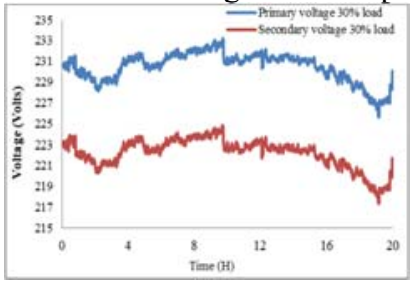

Figure 4: Primary and secondary voltage signatures

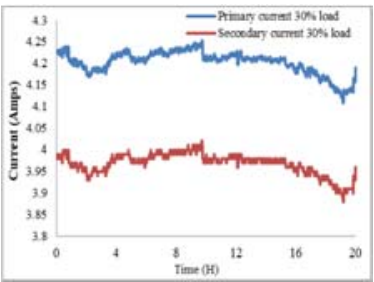

Figure 5: Primary and secondary current signatures

\section{B. Temperature for Healthy Transformer}

The transformer was running at a constant load and the temperature was recorded at intervals of 30 s over the period of 20 Hours, this time period was required to reach the steady state when $30 \%$ of the load was applied. T-ambient, T-Top and T-Bottom of the core and winding temperatures are continually recorded using the thermocouples as in Figure 2. Figures 6 and 7 show the temperature reported by three thermocouples for the running period at the primary and secondary windings. Figure 8 shows the temperature at the top and bottom of the core and the ambient temperature for the running period. It can be seen that the ambient temperature varies between $20{ }^{\circ} \mathrm{C}$ to $23{ }^{\circ} \mathrm{C}$. The internal temperature rises shortly after power is applied and continues to do so until reaching the steady state: it remains at this level while the supplied voltage, load and ambient temperature remain consistent.

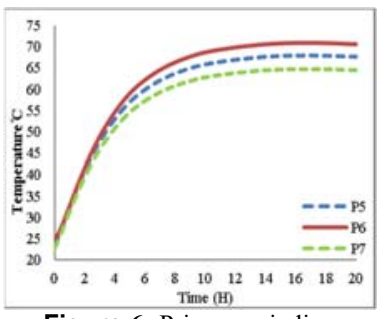

Figure 6: Primary winding temperature

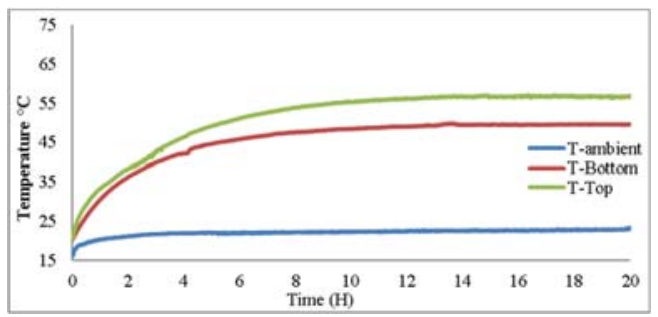

Figure 8: Temperature at the top and bottom of the core and ambient temperature for the running period

\section{Summary of Healthy Transformer Conditions}

As a result of monitoring the voltage and current signatures in both sides of the transformer and the operating temperature for constant load, the characteristics which relate to healthy winding conditions can be classified as below; otherwise care should be taken for the transformer.

- Signatures of voltage and current in both sides of the transformer have same profiles.

- The difference between the primary and secondary voltage remains constant for a fixed load.

- The difference between the primary and secondary currents remains constant regardless of load.

\section{FAUlty TRAnSFORMER TESTINGS}

To identify indicators of unhealthy transformers, several tests have been conducted during operation by shorting different numbers of turns in either primary or secondary winding. However, due to the risk of damaging the transformer from the high local circulating current that is generated by the short circuit, the test could not be conducted at $230 \mathrm{~V}$. A supply voltage of $47 \mathrm{~V}$ and constant load of $2.66 \%$ VA of the rated power was experimentally determined to allow the experiments to be performed safely.

The maximum number of turns that could safely be shorted in the primary or secondary windings is 4 . After the fault has been inserted the transformer was powered in order to determine the indicators on reaching the faulty steady state operation, so that full information on the electric signature and temperature for the faulty transformer can be obtained. This procedure is also applied for the secondary winding tests; however, due to consideration for the safety of the transformer and the high value of current circulating in the secondary winding shorted turns, it was not possible to run the transformer with shorted 4 turns in the secondary winding for a long enough time to reach the steady state.

The data collected from running the transformer for healthy and different number of shorted turns in both windings with a constant load, are as follows;

- Voltage/current signatures for healthy and faulty transformer.

- Currents circulated between the arc and shorted turns.

- Transformer temperature for healthy and faulty transformer.

Data from testing of 2-turns shorted in primary and secondary winding are discussed below.

\section{A. Two-turns Short Circuit in Primary Winding}

The transformer electrical signatures and temperature are used to investigate the effect of fault location on the indicators. At first, the insulation of the transformer has been tested to ensure that the insulation condition is healthy; this test is applied for each experimental case.

\section{1) Electrical behaviour for shorted primary winding}

In this test, the healthy transformer was running for a period of time to reach the steady state operation and, thereafter, two turns are shorted in the primary winding. Electrical signals in both windings are recorded. It is recorded that the primary winding current is the only factor that is affected by the primary winding short circuit, as shown in Figure 9, therefore, the voltages' signatures are not presented. This leads to an increase in the difference between the currents as the secondary current is not affected by this type of fault. 


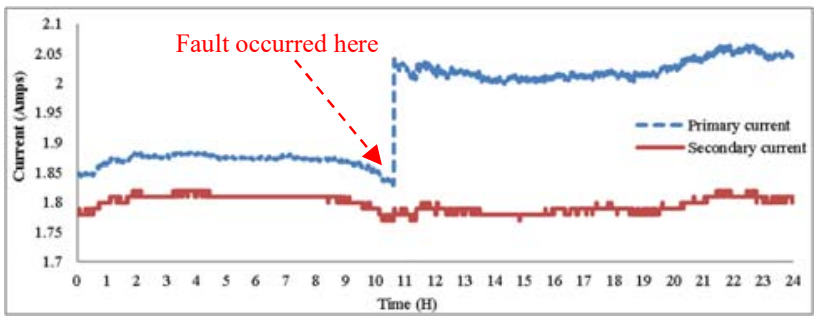

Figure 9: Current signatures for 2-turns short circuited primary winding

2) Temperature behaviour for shorted primary winding

Figure 10 shows the primary winding temperature from 8 thermocouples distributed as shown in Figure 2, the impacts of short circuit on winding temperature is very notable irrespective of the sensor location. As expected, the primary winding current increased due to the short circuit fault, thus, primary winding starts generating additional heat inside the transformer housing, i.e. the circulating current in the shorted turns generates additional heat. The generated heat is distributed inside the transformer tank by convection and conduction. It should be noted that, as the short circuit bridge is created outside the transformer housing (for the sake of experiment), the heat generated by the external current does not affect the thermal behaviour of the transformer in this experiment. However, practically there are three temperature sources instead of two, i.e. the increment of the primary winding current and two circulating currents at the fault location, one part of the circulating current is through the shorted turn and the other is the arc current through the insulation.

Moreover, the temperatures recorded by the sensors are affected by the additional heat sources due to the fault, e.g. the temperature reported by $\mathrm{P} 7$ was the lowest for the healthy transformer but became the highest during the fault. If temperature sensors existed in a field transformer, the temperature could be used to confirm any changes in electric parameters. As indicated in Figure 9, there was no change in current in the secondary winding as a result of the shorted turns in the primary. However, it was noted that, due to air circulation inside the transformer, heat generated due to the fault is distributed inside the transformer housing and the thermocouples located in the secondary winding have recorded the rising of the temperature at the secondary coil and an increased steady state temperature for the faulty transformer, Figure 11 shows the secondary winding temperature for this case.

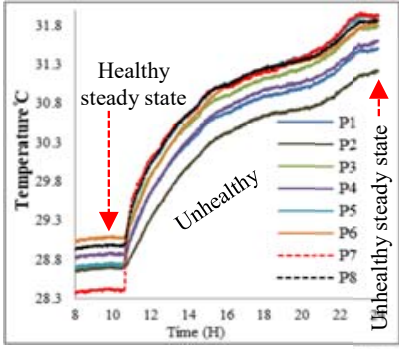

Figure 10: Primary coil temperature for healthy and two shorted turns in primary winding

The temperature at the top and the bottom of the core have been monitored to indicate the effect of the short circuit on the core losses, as the main path of the flux linking the windings is the core itself. Core loss, due to hysteresis and eddy current effects, is dissipated as heat inside the tank, thus, the core temperature has been monitored for an accurate indication. Figure 12 presents the change in temperature of the core for the healthy and faulty cases, it can be seen that the temperature rise at the top and bottom of the core is similar to the rise at the top and bottom of the secondary coil during the fault. The similarity in the temperature rises in the two components suggests that the core losses remain constant or their effect on temperature is too small to use as a diagnostic element.

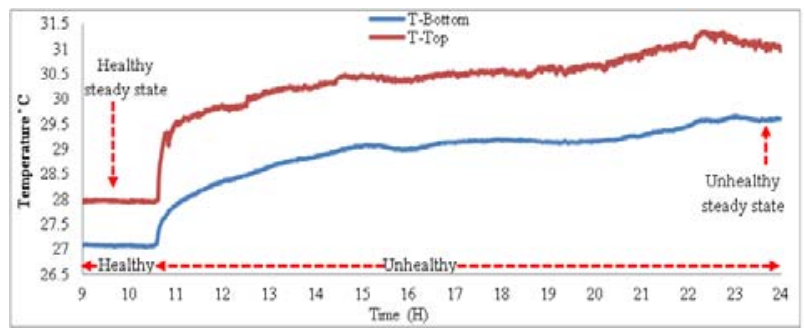

Figure 12: Temperature at the top and bottom of the core for two shorted turns in primary coil

\section{B. Two-turns Short Circuit in Secondary Winding}

Similar to the study above for primary winding short circuit, two-turns short circuit in the secondary winding is investigated.

1) Electrical behaviour for shorted secondary winding

In this test, two turns were shorted in the secondary winding. Figure 13 illustrates the voltage signatures for the running period, it can be seen that the primary winding voltage is behaving normally and following the supply voltage even after the fault has occurred. However, it can be clearly noted that the secondary voltage suddenly dropped when the fault is created. Figure 14 illustrates the current signatures for the running period. It can be noted that for healthy transformer, the current signatures follow the reference (primary voltage) behaviour but, at the fault occurrence the secondary voltage dropped and the current signatures are significantly affected.

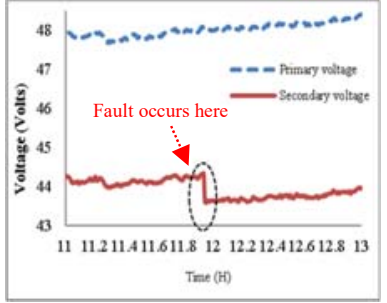

Figure 13: Voltage signatures for

2 turns short circuited in secondary winding

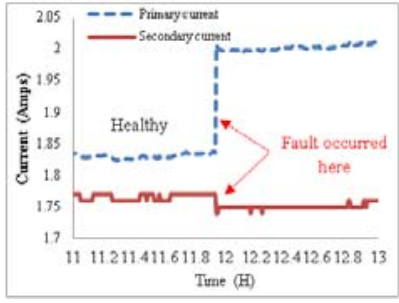

Figure 14: Current signatures for 2 turns short circuited in secondary winding
The secondary winding current drops in accordance with the secondary voltage (given a resistive load is defined, if the voltage decreases then the current should also decrease) but the primary winding current increased. The ability to identify changes in the measured signatures during operation gives an idea of the benefit of on-line monitoring of the transformer signatures.

\section{2) Temperature behaviour for shorted secondary winding}

The fault was created in the secondary winding, but the electric parameters indicate that primary winding current increases when the fault occurs in the secondary winding; as discussed earlier, therefore, the heat sources exist in the 
vicinity of primary and secondary winding: heat is distributed in the transformer tank generating a new steady state temperature; Figure 15 presents the primary winding temperature for healthy and faulty transformer; although the ambient temperature has decreased, the transformer temperature has been increased due to the fault. It can be seen that temperatures recorded through thermocouples P7 and $\mathrm{P} 8$ are rising most compared to the other sensors reading when the fault has occurred due to the fault location is closer to the sensors.

Figure 16 presents the secondary winding temperature reported by the thermocouples distributed in the secondary coil. The measured electrical signatures indicate that the primary winding current increases and leading to generation of additional heat in the faulty transformer. Due to the current circulating in the secondary shorted turns, the temperature rising reported for the secondary winding is higher than that reported for the primary winding. The core loss will increase as the primary winding loss increases due to increasing the hysteresis loss, Figure 17 shows the difference between the core steady state temperature for healthy and un-healthy transformer. Core temperature cannot indicate whether the fault occurs in the primary or secondary winding, however it can be used to indicate the core loss when different number of shorted turns have occurred, this will be discussed in details in the section of investigating the fault severity.

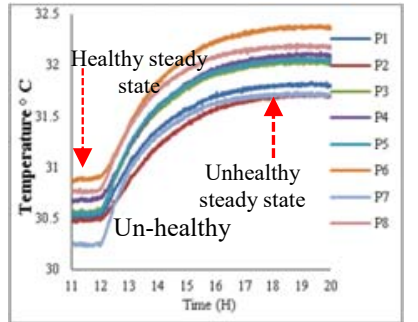

Figure 15: Primary coil temperature for two shorted turns in secondary winding

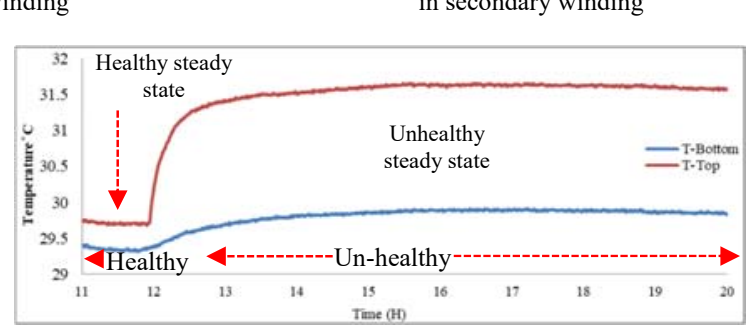

Figure 17: Temperature at the top and bottom of the core for two shorted turns in secondary coil

\section{Precise Fault LocAtion}

In order to identify the fault location during operation, electrical signatures from both sides of the transformer and the recorded winding temperatures are considered. When a fault is detected in a transformer the recorded data can be used to indicate whether a short circuit has occurred in the primary or secondary coil. The temperature analysis is used to confirm that a fault has been detected and to indicate the location of the short circuit in the transformer. The following rules have been developed for fault location identification:
1- If (a) the three signatures primary current, secondary voltage and secondary current are behaving normally and are following the variation of the reference primary voltage, and (b) the recorded temperature is at the expected value for the steady state given the supplied voltage, load applied and the ambient temperature, then the transformer is operating normally.

2- If the primary current has suddenly increased and secondary winding signatures are not affected, a short circuit is expected to have occurred in the primary winding.

3- If the three signatures are suddenly changed and are not following the primary winding voltage, i.e. where the primary winding current increases, secondary winding current decreases and secondary voltage decreases, then a short circuit is expected to have occurred in the secondary winding.

4- If the recorded core temperature is not at the expected value for the steady state given the supplied voltage, load applied and the ambient temperature, then the transformer is not operating normally.

5- Analysing the temperature data reported by the distributed sensors at the top and bottom of the primary and secondary coils, could indicate the fault location based on the additional heat generated by the circulating current at the fault location.

Following the above five steps will identify the faulty winding, the next step is to find the main location of the short circuit inside each winding. The winding construction and distribution of the temperature's sensors should be accurately specified and mapped. One of the most important advantage of distributing temperature sensors in the winding is to indicate the short circuit location based on the thermal changes following a fault. In practice when a short circuit occurred, there are two sources of heat, one due to the fault current and the other in the insulation air or oil.

To demonstrate the identification of a main short circuit location in a faulty winding, the detection of two shorted turns in a primary winding (identified in red in Figure 2) is discussed. Thermocouple P7 is the nearest to the fault location, therefore, it is clear from Figure 18 that P7 is recording the highest change in the temperature, meaning the fault is in its vicinity.

As a result of comparing the temperatures' signature behaviour at the top sensors to the bottom sensors, it can be confirmed that temperature signatures at the bottom of the winding are rising steeply compared to the top ones. This confirming the location of the fault.

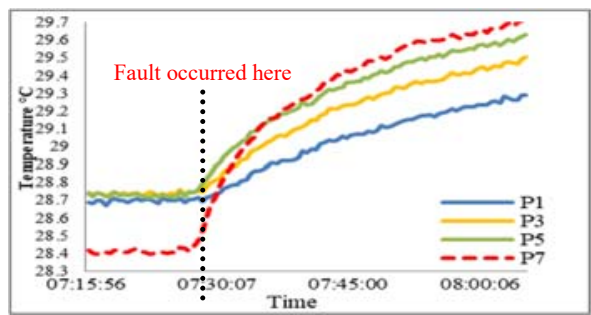

Figure 18: Temperatures signature at the bottom of primary winding

\section{FAULt SEVERITY}

When the fault has been detected, it is very important for the transformer owner to investigate the fault severity, in order to plan maintenance, future operation or replacement of the transformer. One of the advantages of applying on-going condition monitoring of power transformer is the ability to classify the fault severity.

In this work, the fault severity will be investigated based on a combination of the electrical and heat parameters. 


\section{A. Fault Severity-Current Signitures}

Figure 19 illustrates the measured primary winding current for faulty primary winding. As expected, the higher number of shorted turns in the primary winding leads to increasing the primary current. Therefore, the increment in the current can indicate the severity of the fault and predict the number of shorted turns.

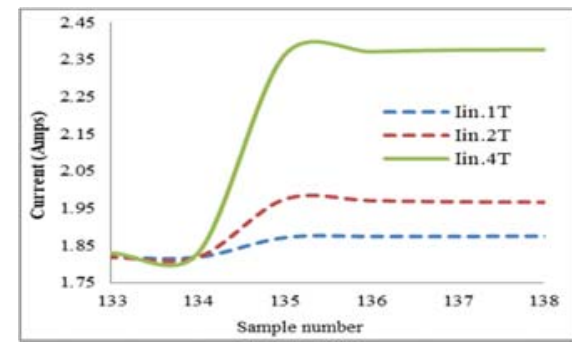

Figure 19: Primary winding current for different number of primary shorted turns

\section{B. Fault Severity-Temperature Sigintures}

Figure 20 shows the corresponding temperature record for the same series of faults, thermocouples that attached to the faulty disc (P7) can be used to indicate the fault severity along with the measured electric parameters. As it has been investigated that higher number of shorted turns leading to sudden increase of the primary winding current and consequently the temperature, therefore, this relation can be also used to indicate the fault severity but it cannot be used to indicate the short circuit location. This confirms the classification of the severity of the faults and indicates the number of turns involved.

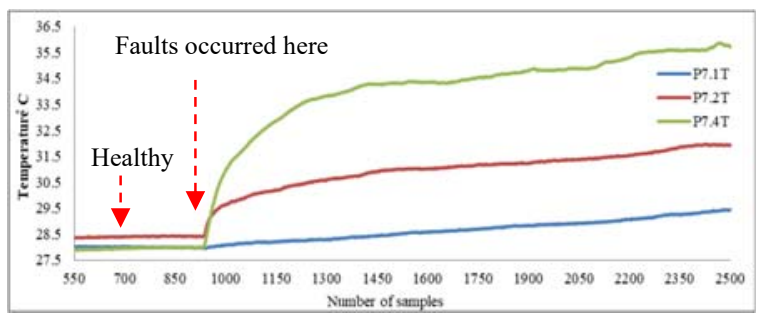

Figure 20. Comparison of the actual temperature for indicating the fault severity

\section{CONCLUSIONS}

The main focus of this work is to investigate the possibility of monitoring the transformer during operation, based on the measured signatures electrical (current and voltages in both windings) and thermal. Different numbers of shorted turns have been tested in the primary and secondary winding in order to investigate the transformer behaviour. The results confirmed that when a short circuit occurs, changes of the transformer behaviour electrically and thermally can be clearly noted. Thereafter, analysis of the measured parameters confirmed the fault occurrence and its location. The increment of the winding currents can be used to indicate the increment of the short circuit circulating current, thus the fault severity can be classified. The temperature measured using all thermocouples have been used to indicate the faulty windings and, moreover, to indicate the faulty disc in each winding.

\section{References}

[1] IEC 60076-1, International standard, Power Transformer General, $3^{\text {rd }}$ Edition 2011

[2] H. Berg and N. Fritze, "Reliability of main transformers," Reliability:. Theory and Applications., vol. 2, no. 1, pp. 52-69, 2011.
[3] R. Schwarz and M. Muhr, "Diagnostic methods for transformers," Condition Monitoring and. Diagnosis, International Conference on IEEE, pp. 974-977, 2008.

[4] Serveron, "On-Line transformer monitor operation \& maintenance guide," www.serveron.com, Serveron Corporation Report, A BPL Global Company, pp. 1-20, 2010.

[5] L. Oliveira and A. Marques Cardoso, "Leakage Inductances Calculation for Power Transformers Interturn Fault Studies," IEEE Trans. Power Deliv., vol. 30, no. 3, pp. 1213-1220, 2015.

[6] M. Erol-Kantarci and H. Mouftah, "Energy-Efficient Information and Communication Infrastructures in the Smart Grid: A Survey on Interactions and Open Issues," IEEE Commun. Surv \& Tutorials, vol. 17, no. 1, pp. 179-197, 2015.

[7] J. Kumar and U. Perasadr, "Expert System for Sweep Frequency Response Analysis of Transformer Using MATLAB," Inter. Jou. Scien. \& Resea. public, vol. 2, no. 12, pp. 1-13, 2012.

[8] J. Gonzales and E. Mombello, "Fault Interpretation Algorithm Using Frequency-Response Analysis of Power Transformers," IEEE Trans. Power Deli, vol. 31, no. 3, pp. 1034-1042, 2016.

[9] Y. Liu et al., "A study of the sweep frequency impedance method and its application in the detection of internal winding short circuit faults in power transformers," IEEE Trans. Dielectr. Electr. Insul., vol. 22, no. 4, pp. 2046-2056, 2015.

[10] H. Mirzaei et al , "Advancing new techniques for UHF PDdetection and localization in the power transformers in the factory tests," IEEE Trans. Dielectr. Electr. Insul., vol. 22, no. 1, pp. 448-455, 2015.

[11] J. Liu and V. Dinavahi, "Nonlinear Magnetic Equivalent Circuit-Based Real-Time Sen Transformer Electromagnetic TransientModel on FPGA for HIL Emulation," IEEE Trans. Power Deliv., vol. 31, no. 6, pp. 2483-2493, 2016 .

[12] G. Kumbhar and S. Kulkarni, "Analysis of short-circuit performance of split-winding transformer using coupled field-circuit approach," IEEE Trans. Power Deliv., vol. 22, no. 2, pp. 936-943, 2007.

[13] M. Lambert et al, "Analytical calculation of leakage inductance for low-frequency transformer modeling," IEEE Trans. Power Deliv., vol. 28, no. 1, pp. 507-515, 2013.

[14] P. Rajamani and S. Chakravorti, "Identification of simultaneously occurring dynamic disc-to-disc insulation failures in transformer winding under impulse excitation," IEEE Trans. Dielectr. Electr. Insul., vol. 19, no. 2, pp. 443-453, 2012.

[15] P. Reddy and B. Rajpurohit, "On-Line Monitoring of Winding Parameters for Single-Phase Transformers," IEEE $6^{\text {th }}$ India Inter. Conf. on Power Electro, pp. 1-4, 2014.

[16] P. A. Venikar, et al "A novel offline to online approach to detect transformer interturn fault," IEEE Trans. Power Deliv., vol. 31, no. 2, pp. 482-492, 2016.

[17] C. Yao, Z. Zhao, and Y. Mi, "Improved Online Monitoring Method for Transformer Winding Deformations Based on the Lissajous Graphical Analysis of Voltage and Current," IEEE Trans. Power Deliv, vol. 30, no. 4, pp. 1965-1973, 2015.

[18] A. S. Masoum et al " "Online transformer internal fault detection based on instantaneous voltage and current measurements considering impact of harmonics," IEEE Trans. Power Deliv., vol. 32, pp. 587-598, 2017.

[19] A. Abu-Siada and S. Islam, "A novel online technique to detect power transformer winding faults," IEEE Trans. Power Deliv., vol. 27, no. 2, pp. 849-857, 2012.

[20] E. Aburaghiega, M. Farrag, D. Hepburn and B. Garcia, "Power Transformer Health Monitoring: A shift from off-line to on-line detection," 50 $0^{\text {th }}$ Inter.(UPEC), pp. 1-6, 2015.

[21] E. Aburaghiega, M. Farrag, D. Hepburn and B. Garcia, "Advanced online condition monitoring of, and inter-turn short circuit setectionin, power transformers" 53rd Inter.(UPEC), pp. 1-6, 2018

[22] "Labfacility datasheet and hand book". A practical Guide to Measure Temperature, Control and Calibration using Thermocouples and Resistance Thermometers, published in 2003. 